\title{
ERRATUM
}

\section{Erratum to: Bromate removal by gamma irradiation in aqueous solutions}

\author{
Zhao-Lian $\mathrm{Ye}^{1} \cdot$ Xue-Hui Fang ${ }^{1} \cdot$ Hui-Qi Hou ${ }^{2}$
}

Published online: 10 March 2016

(C) Shanghai Institute of Applied Physics, Chinese Academy of Sciences, Chinese Nuclear Society, Science Press China and Springer Science+Business Media Singapore 2016

\section{Erratum to: NUCL SCI TECH (2016) 27:3 \\ DOI 10.1007/s41365-016-0003-z}

In this paper, all ".e $\mathrm{e}_{\mathrm{aq}}^{-}$" should be corrected into " $\mathrm{e}_{\mathrm{aq}}^{-}$", i.e., the "dot" in the ". $e_{a q}^{-}$" must be deleted.

That means all ".e $e_{\mathrm{aq}}^{-}$", in both the context and equations, should be replaced by " $\mathrm{e}_{\mathrm{aq}}^{-}$".

The online version of the original article can be found under doi:10.1007/s41365-016-0003-z.

Zhao-Lian Ye

bess_ye@jsut.edu.cn

1 College of Chemistry and Environmental Engineering, Jiangsu University of Technology, Changzhou 213001, China

2 Department of Environmental Science and Engineering, Fudan University, Shanghai 200433, China 